\section{Invitational Synthesis Paper}

Dr. Paul T. Tueller is Professor of Range Ecology in the Department of Range, Wildlife and Forestry, University of Nevada Reno. Paul has had over 30 years as student and professor working in the general area of Range Ecology and Management. He has initiated numerous studies concerned with range ecology, vegetation-soil relationships, range condition and trend, big game habitat management, brush encroachment, ecology of the pinyonjuniper woodland, mine waste reclamation, and remote sensing with emphasis on arid lands. Other qualifications include: commercial instrument rated pilot with over 3,000 hours, currently Associate Editor, Journal of Range Management, Certified Range Management Consultant.

\section{Remote sensing technology applications}

\author{
PAUl T. TUELleR
}

\section{Abstract}

The future of rangeland resources development and management is dependent upon increased scientific capability. Remote sensing technology can contribute information for a variety of rangeland resource management applications. In future we can expect to see an increased number of professional range managers with expertise in remote sensing. This training will include, in addition to principles of aerial photo interpretation, digital image analysis technology, increased use of geographic information systems, airborne video remote sensing, and the use of newly developing high resolution systems. The data will be obtained from both aircraft and spacecraft. Applications will include inventory, evaluation, and monitoring of rangeland resources and the incorporation of remote sensing data to support and improve the decision processes on the use, development, and management of rangeland resource areas.

Key Words: Remote sensing, aerial photography, color infrared, spectral characteristics, vegetation mapping, vegetation monitoring, range management, geographic information systems, airborne video.

The art and science of range management is being pushed to new heights as practitioners and scientists approach the future. Changes in range management are inevitable. Expectations of high technology will be realized only when range professionals are able to apply new scientific developments to important rangeland resource management problems. Remote sensing, the acquisition of information concerning an object or phenomenon without physical contact, is one such scientific discipline and the subject of this paper. Rangeland resource management will become strongly dependent upon increasingly sophisticated, holistic approaches. Remote sensing, along with Geographic Information Systems (GIS), can provide a fresh approach to the use, development, and management of rangelands throughout the world.

Remote sensing has been recommended for at least 30 years for assisting with rangeland resources development and management on a worldwide basis (Tueller 1982). A history of remote sensing for range management is found in Poulton et al. (1975) and Poulton (1985). These histories go back well in to the 1930s when aerial

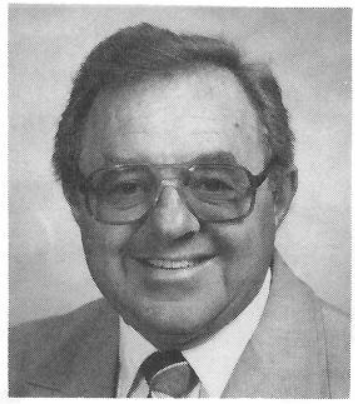

Paul T. Tueller

\title{
for rangeland management
}

photography was first used. The first black-and-white aerial photography at the usual scale of about $1: 20,000$ became available for range-resources investigations in 1935 and 1936 (Moyer 1950). Poulton's history further describes the development of remote sensing as a science in the mid-to-late 1960s. The launch of Landsat 1 in 1972 ushered in a new era extending remote sensing beyond air photo interpretation into the realm of digital analysis of multispectral and multitemporal data.

The collective area of rangeland is large; if forested ranges and natural vegetation in tropical savanna and tundra areas are included, the total land area of rangelands may be as high as $47 \%$ of the global land surface (Williams et al. 1968). Due to the extensive nature of rangelands and the recognized need to manage them at low cost, remote sensing is considered to have significant promise for the future.

Remote sensing is more than high quality color and color infrared photographs and digital image manipulation. Rather it is, in itself, an art and a science. The science is provided mostly by engineers, physicists and computer specialists who have increased our abilities to exploit information inherent in various regions or wavebands of the electromagnetic spectrum. Range scientists contribute specialized knowledge and interpretation. The proper interpretation and application of remote sensing is an art. Inherent in this is the importance of developing an understanding of the ecology of the landscapes and of the vegetation-landform-soil relationships as a basis for image interpretation.

The basic logic of remote sensing is the logic of inference. If cause $C_{1}$ exists, then effect $E_{1}$ will be observed, and if effect $E_{1}$ is observed, then cause $C_{1}$ must exist. In other words remote sensing interpreters can study certain features directly and other features only indirectly by inference or association. We are using the concept of surrogates wherein we identify and measure easily observed (via remote sensing) features that are related to more complex features or phenomena that a range scientist or manager wishes to identify, measure, and judge the significance of. For example, it is possible to measure crown cover of shrubs on a large-scale vertical aerial photograph; but it is quite difficult, if not impossible, to accurately measure height or biomass. Research in remote sensing 


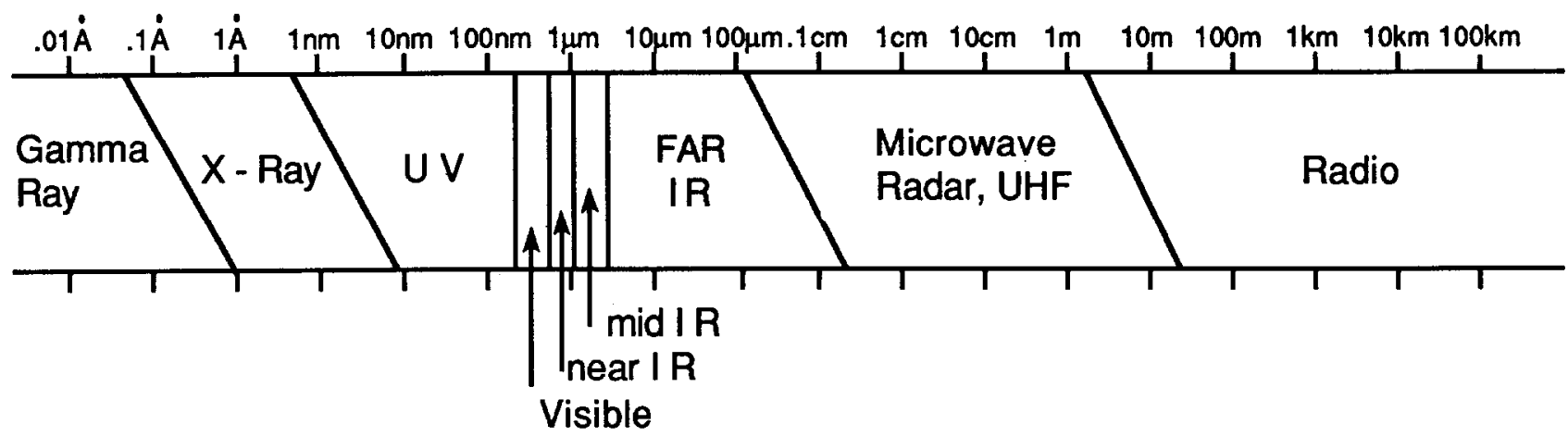

Fig. 1. The visible, near infrared, mid infrared, thermal or far infrared and microwave regions of the electromagnetic spectrum provide potential remote sensing applications for range management.

is required to establish useful and unique inferential relationships that are relevant to range management decision processes.

\section{Remote Sensing Procedures or Systems}

Remote sensing information is derived from measurements of electromagnetic radiation by air-or satellite-borne cameras, video cameras, ultraviolet and infrared detection apparatus; radar and radio frequency receivers; the measurement of acoustical energy by seismographs, sonar and microphones; the measurement of nuclear or ionizing radiation; and the measurement of force fields by gravimeters and magnetometers (Willow Run Laboratories 1978). The latter 3 forms of remote sensing have not been used extensively for rangeland resource management. This paper will emphasize imaging and digital remote sensing in the visible, near infrared, mid infrared, far or thermal infrared, and microwave sections of the electromagnetic spectrum (Fig. 1).

\section{Aerial Photography}

The most used form of remote sensing has been aerial photography. Aerial photographs still provide the highest resolution and capture the spatial and textural essence of the scene with greater fidelity than any other procedure. Disadvantages include the cost of repeated coverage for change detection, including the costs of film and processing, and the limited spectral sensitivity of conventional photography.

Photogrammetry, the making of measurements from photographs includes stereoscopic viewing, which permits the measurement of height and the evaluation and interpretation of terrain features. Photo interpretation includes the use and evaluation of several important factors often referred to as the photo interpretation principles: color, tone, texture, pattern, shadow, size, shape, and convergence of evidence (several different but related characteristics when combined lead to correct interpretations). In photo interpretation the human mind acts as the master manipulator and integrator of information leading to an accurate interpretation. For many rangeland uses this approach is still the most fruitful.

\section{Resolution and Scale}

Resolution is the ability of an entire remote sensor system, including lens, antennae, display, exposure, processing, and other factors, to render a sharply defined image (Colwell 1983). For aerial photography it is usually considered in 1 of 2 ways: first as effective ground resolution, which can be defined as the size an object must be before it can just be identified as a discrete entity on an aerial photograph or image, and secondly as the number of contrasting black and white line pairs of a given size and spacing that can be differentiated per millimeter or meter as viewed on a standard test target. The term image in remote sensing is a broader term than "photograph." Photographs are images, but images also include radar scenes, thermograms, video pictures, and other data displayed in a picture-like form such as a laser scan. Also by combining various wavebands of the spectrum, we can produce a product similar to an aerial photograph but derived in an altogether different way.

Much of the remote sensing data we are concerned with is obtained with a scanning radiometer, which by the use of a rotating or oscillating plane mirror can scan a path normal to the movement of the radiometer. The mirror passes radiant energy to one or more detectors that record the energy from various wavelengths of the electromagnetic spectrum. Resolution for a scanning radiometer system is expressed in terms of an instantaneous field of view (IFOV). This denotes a narrow field of view designed into the detectors of a scanning system, so that while as much as $120^{\circ}$ may be under scan, only electromagnetic radiation from a small area is being recorded at any one instant. This refers to the physical dimension on the ground within which one datum point, or spectral reflection or emission value, is recorded by the sensor system. This area is referred to as a pixel (picture element) which determines the minimum feature size that is represented by a unique signature in the spectral data set. Normally ground features of interest are represented by the data in a few to many pixels.

Scale is an important concept related to resolution. Representative fraction scales (the ratio between the distance on the photograph to the actual ground distance) are used to determine the size of objects on a photo or image. Scales of remote sensing image products can vary from as large as $1: 100$ to as small as $1: 5,000,000$ or smaller, all of which can be used by range managers. Digital data can be used to produce hard copy images at a variety of scales, the largest of which are difficult to interpret because of their low resolution.

\section{Spatial, Temporal, and Spectral Resolution}

In addition to spatial resolution (related to scale), remote sensing also has aspects of both temporal and spectral resolution. Spatial resolution is used in resource management, including range management, in a multistage sampling approach (Langley 1971). In multistage sampling, the remote sensing user evaluates the resource first on small-scale imagery or photography giving a synoptic or large-area view. This enables one to examine the ecological and land use patterns over distances of 10's of kilometers. Images at incrementally larger scales provide increasing detail about smaller areas. Inferences from representative sites within large scale images are extrapolated back to the smaller scales giving a summation of the total resource within the area of interest, providing sampling has been adequate and all categories of interest have been included. Often this is accomplished using statistical techniques such as sampling with probabilities proportional to sample size (PPS).

Temporal resolution can be referred to as multidate remote sensing and is used for change detection or monitoring. Several 


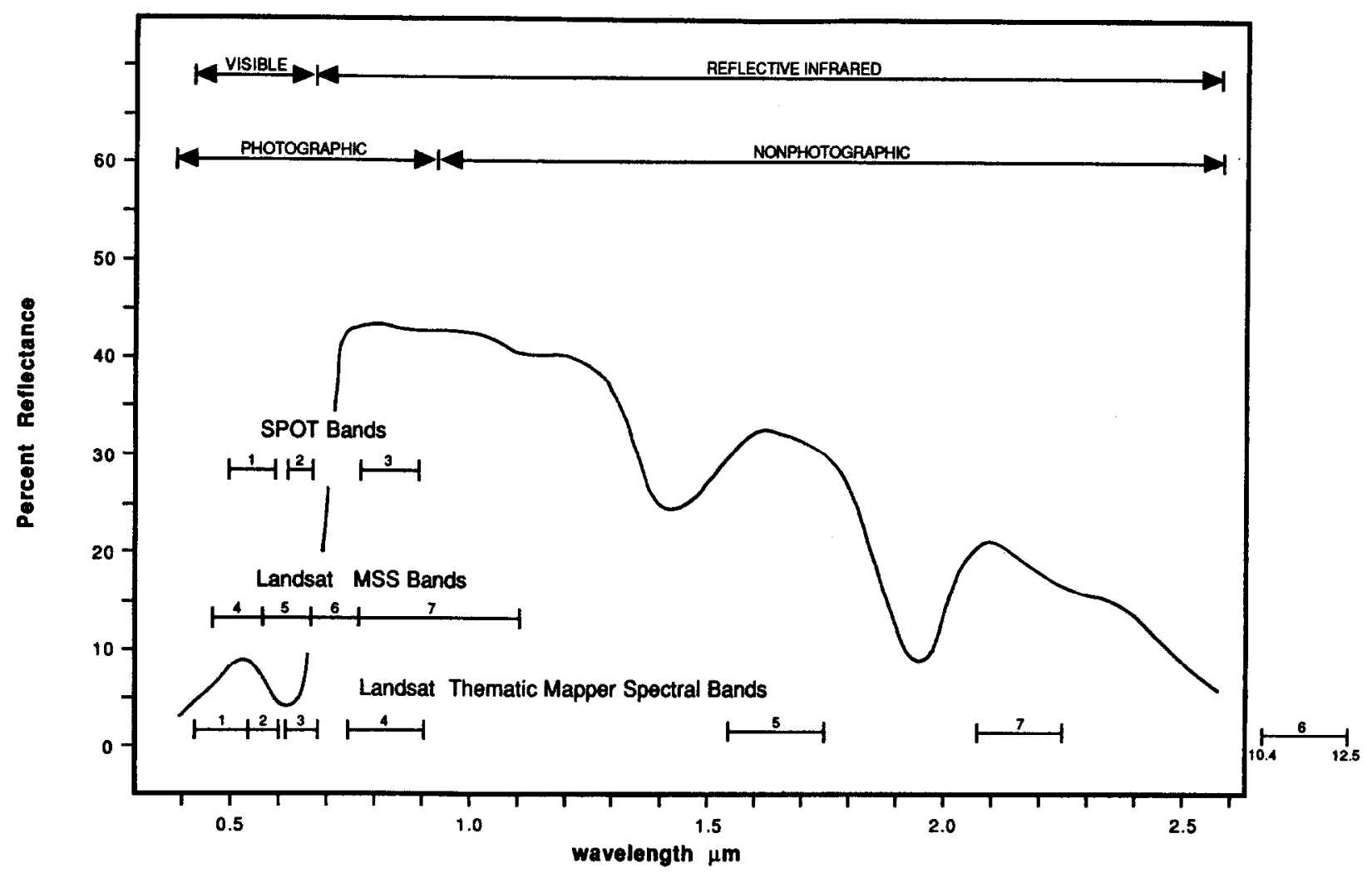

Fig. 2. The spectrum of a typical green plant showing areas of high and low reflectance and the location of the visible and reflective infrared, the photographic and non-photographic wavelengths, and the Landsat TM and SPOT wavebands.

change detection algorithm alternatives are available including image differencing, image ratioing, classification comparison, comparison of preprocessed imagery, and change vector analysis based on changes between sampling dates in spectral appearance of the features in the scene (Jensen 1981). Two good examples in range management are the assessment of vegetation change (range trend) and the evaluation of utilization differences brought about by differential use of various pastures in a grazing management system.

Somewhat paralleling the use of optical filters in conventional photography, acquisition of the multispectral scanner data allows one to much more finely control the wave-length window, or amount of the electromagnetic spectrum, that is used to establish one datum point. The width of this spectral window is referred to as spectral resolution. They can be very broad, i.e., 1 band can encompass all the green light or reflective infrared energy in a single band or measurement (thus a single datum point), or each can be broken down into 2 or more bands, each with its own set of data points. These readings can be made for large or small IFOV's, i.e., ground resolution cells (pixels). Multispectral reconaissance or multispectral sampling, refers to the concept of looking at the same feature or polygon with several of these discrete bands or wavelengths of the electromagnetic spectrum. Each band or combination of bands provides new or unique information about a resource feature.

\section{MSS, TM, SPOT and AVHRR}

Numerous spacecraft, both past and present, have been used to acquire remotely sensed data. Some of the systems presently in use are the Landsat Multispectral Scanner (MSS) flown on Landsats 1,2 , and 3 which has 4 channels, 2 in the visible part of the spectrum and 2 in the near infrared; the Landsat Thematic Mapper (TM) flown on Landsat 4 and 5 which has 7 channels 3 in the visible part of the spectrum, 1 in the near infrared, 2 in the mid infrared or water absorption region and a thermal channel: the SPOT (Systeme Pour l'Observation de la Terre) which has 3 channels, 2 in the visible and 1 in the near infrared (Fig. 2); and the AVHRR (Advanced Very High Resolution Radiometer), with 5 channels, 1 in the visible, 1 in the near infrared, 1 in the mid infrared, and 2 thermal channels. All are multispectral imaging sensors. The AVHRR is a multispectral imaging sensor that was designed to permit detection and discrimination between clouds, land, water, snow, and ice.

MSS data has pixels approximately $80 \mathrm{~m}$ on a side and the TM pixels are $30 \mathrm{~m}$ on a side. SPOT data from the French Satellite has $20 \mathrm{~m}$ pixels. In addition SPOT has a single panchromatic black and white band with $10 \mathrm{~m}$ resolution. The imagery from these 2 systems can be co-registered, giving effective $10 \mathrm{~m}$ resolution of color and color infrared products. These systems have relatively wide spectral bands compared with the high resolution remote sensing systems currently under development. The orbital characteristics of these result in repeat coverage of the same ground area at regular intervals between 9 and 18 days. In the case of SPOT, repeat coverage of selected sites can be accomplished more often because the scanning instrument can be pointed to areas not directly underneath the satellite.

The NOAA weather satellites provide remotely sensed data at a scale of $1: 10,000,000$ and resolution cells or pixels that are approximately $1 \mathrm{~km}$ on a side from AVHRR. AVHRR data have been used to study desertification in the Sahel (Tucker and Justice 1983; Tucker et al. 1985) and to study large grazing piospheres in Australia (Graetz and Ludwig 1978). One advantage to this system is the capability of obtaining data on a daily basis. A disadvantage is the low resolution. These data are useful where daily synoptic views 
with multispectral data are required. An example on rangelands would be to examine range readiness and fire fuel hazard for an entire mountain range or several mountain ranges as such parameters change on a daily basis.

\section{Radar Systems}

Microwave systems have potential for rangeland applications. These include both Side Looking Airborne Radar (SLAR) and Synthetic Aperature Radar (SAR). SLAR allows a relatively wide swath to be imaged. SAR allows the creation electronically of long aperatures capable of greater resolution. These systems are useful because they are not constrained by either night (darkness) or cloud cover. They create their own signals that are reflected back from the earth's surface giving imagery that has utility for vegetation mapping and strong capabilities for looking at terrain features.

Green (1986) used Shuttle Imaging Radar-A (SIR-A) data and found that during periods when most of the vegetation in a shrub rangeland in South Australia was non-vigorous and spectrally homogeneous, the SIR-A data, as a surrogate measure of shrub cover, allowed the reflectance due to shrubs in Landsat data to be separated from the reflectance due to the intervening ground. Radar has potential to measure and monitor soil moisture and may be used in conjunction with other forms of remote sensing as supplemental information for rangeland monitoring. Several other range management applications are feasible with radar data although the cost of most systems and the acquisition of the data currently tends to be prohibitive.

\section{Airborne Scanners}

Several valuable instruments have been developed to be flown as multispectral scanners from aircraft. One such instrument is the Thermal Infrared Multispectral Scanner (TIMS), an aircraftborne scanner providing six-channel spectral capability in the thermal infrared $(8.2-11.7 \mu \mathrm{m})$ or that portion of the infrared that has thermal or emitted heat sensitivity. This instrument was developed at NASA's Jet Propulsion Laboratory. Other airborne scanning instruments include the Thematic Mapper Simulators, TMS and $\mathrm{NSOO1}$. The added feature of measuring surface temperature has been used to map soils in arid regions (Miller et al. 1986). There appears to be some potential for discriminating soil textural features because of the ability of the system to identify emmissivity minima for silicate minerals (Kahle and Goetz 1983). Langran (1985) used TIMS data to monitor vegetation regrowth in primary and secondary disturbance zones on Mount St. Helens. Studies with TIMS and similar data sets suggest a potential application whereby unique temperature-related soil and vegetation type maps of rangelands may be created and updated.

\section{Video Systems}

It may seem somewhat strange to turn now to a relatively lowresolution system such as airborne video. However, it seems clear that the future of resource management will be strongly influenced by video remote sensing systems. Video cameras differ from film cameras. They contain no tape or film and the image is relayed electronically to a video cassette recorder (VCR) for tape storage or to a TV monitor for real-time display.

Video has several attractive attributes, the most prominent of which is the near-real-time availability of imagery. Also video data are relatively inexpensive to obtain. These factors can be very important whenever the application is very time-sensitive or when film and film processing is not available such as in many developing countries. Examples of time sensitivity in range management include surveillance and action to ameliorate wildfires or floods, recording range readiness/phenology, and measuring vegetation changes (monitoring) generated by intensive grazing management.

J.H. Everitt and his colleagues at the USDA/ARS laboratories at Weslaco, TX are pacesetters in airborne video applications, especially for range vegetation studies and range management. In a recent review article, Everitt and Escobar (1989) point out that another advantage of video is the capability of obtaining imagery in very narrow spectral bands $(0.05-0.10 \mu \mathrm{m})$ and in the near and mid-infrared bands. They state that the main disadvantage of video is its low resolution relative to aerial photographs. Typical tape recorder resolution for color and black-and-white video is 240 and 300 lines, respectively, across the format field, whereas 35 -mm slide film resolution has 720 lines across the long axis of the format. The primary reason for the low resolution of video is the recorder. Video cameras are available with at least 1,400 lines of resolution and a new super VHS recorder with over 400 lines of resolution will improve video resolution (Lusch 1988).

Airborne video imaging systems have been evaluated for a variety of rangeland management applications. These have included distinquishing among plant species and mapping rangeland vegetation (Everitt and Nixon 1985) and assessing grass production (Everitt et al. 1986). Video applications for rangeland management will almost certainly escalate in the near future.

\section{High Spectral Resolution Systems}

Physicists and engineers have actively improved remote sensing instrumentation, while application scientists have been researching their feasibility and use. This has resulted in a new area of remote sensing that we might refer to as high spectral resolution remote sensing. Three systems can be mentioned here AIS, AVIRIS, and HIRIS. All 3 of these systems have been developed at NASA's Jet Propulsion Laboratory. AIS (Airborne Imaging Spectrometer) is an instrument that images 32 cross-track pixels simultaneously, each in 128 spectral bands in the $1.2-$ to $2.4 \mu \mathrm{m}$ region (Vane et al. 1984). This system is somewhat lacking in that no data are acquired in the visible part of the spectrum. Preliminary arid land vegetation studies with AIS indicated that brightness was reduced by the vegetation primarily due to shadowing. At periods of peak growth, saltbush and Great Basin sagebrush communities were found to have unique spectral curves (Ustin et al. 1985).

The AVIRIS (Airborne Visible and Infrared Imaging Spectrometer) instrument, has been designed as a successive step in the process of developing systems for high spectral resolution remote sensing of the Earth. AVIRIS covers the spectral region from 0.41 to $2.45 \mu \mathrm{m}$ using bands $10-\mathrm{nm}$ wide. This instrument consists of 4 spectrometers that scan the test site from an aircraft. At any one moment the spectrometers are viewing a 20 -meter square pixel. This pixel is viewed simultaneously in 224 spectral bands. The data are recorded on a tape recorder for later analysis. Computer processing of the data will produce an image of the test site in any one of the 224 spectral bands, the spectrum corresponding to any pixel or group of pixels in the scene (Porter and Enmark 1987).

And into the future, HIRIS (High-Resolution Imaging Spectrometer) is planned for the $1990 \mathrm{~s}$. This instrument will acquire simultaneous images in 192 spectral bands in the dominant wavelengths of the solar spectrum, 0.4 to 2.5 micrometers, at a spectral sampling interval of 10 nanometers. The ground instantaneous field-of-view (GIFOV) will be 30 meters over a 30-kilometer track. In addition a pointing capability will allow image acquisition up to +60 degrees/ -30 degrees down-track and plus or minus 24 degrees cross-track (NASA 1987). This latter feature may someday be very important to range managers interested in evaluating rangeland vegetation for suitability, phenology, carrying capacity, and range readiness since the cross-track pointing will also allow multiple viewing opportunities during one orbital revisit cycle, nominally 16 days.

High resolution systems will enhance the ability of remote sensing procedures to scrutinize the vegetation with much greater 
finesse than heretofore available. For example, Dr. Chris Elvidge of the Desert Research Institute, University of Nevada System, has been pioneering the analysis of vegetation spectra of plant canopies including rangeland species (Elvidge 1989). He and others have hypothesized that high spectral resolution data from aircraft can be used to measure lignin, nitrogen, and both green and non-green (dry leaves, dry reproductive structures, bark, and wood) plant materials. For big sagebrush (Artemisia tridentata) Elvidge's data show great variation in the spectral response of gray bark, gray wood, gray leaves, brown wood, brown flowers and senesced leaves (Fig. 3).

The futur may well allow high resolution remote sensing systems to routinely gather spectral data concerning several species on a rangeland site and provide an instant analysis of the quality, quantity, and condition of rangeland and wildlife habitat forage and browse.

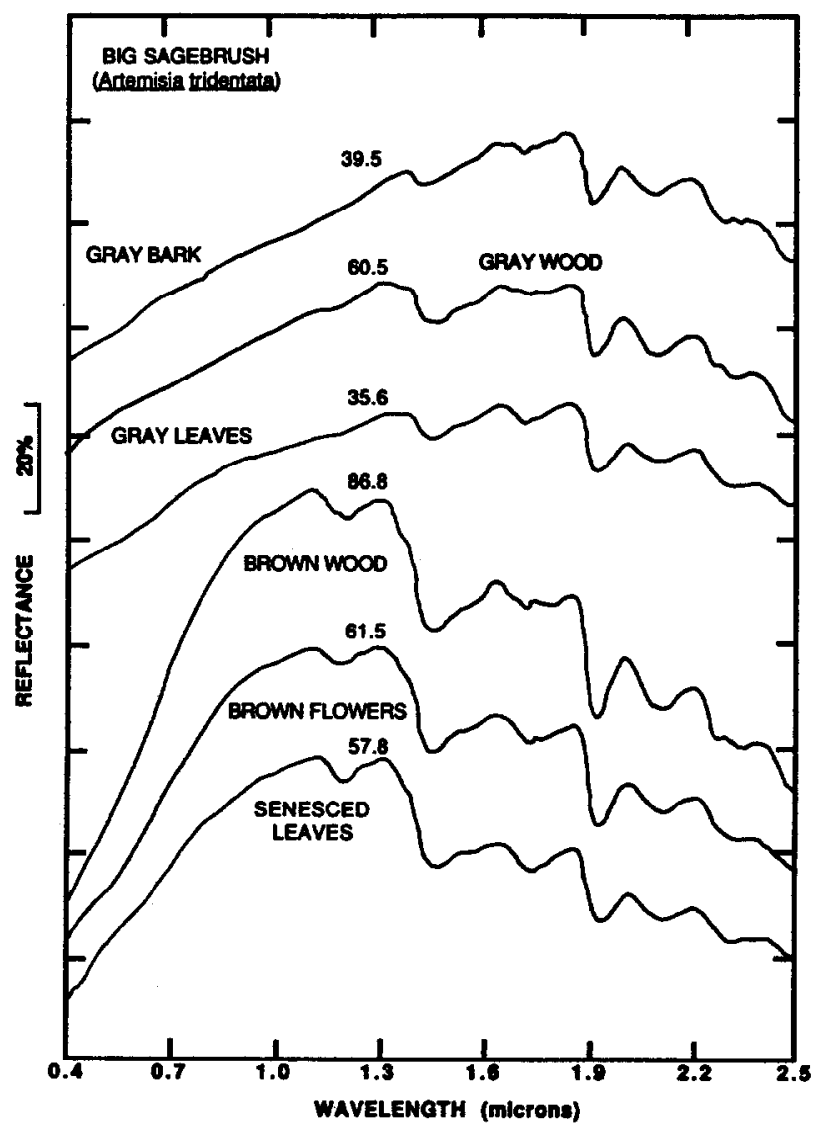

Fig. 3. Sagebrush spectra from Elvidge (1989).

One of the several problems for the future is the prodigious rate at which data can be generated by these systems. Fortunately, it appears that faster and faster computers with ever-growing speed and capacity will allow scientists, including range scientists, and managers to analyze the data sets coming from these instruments and make the information readily available and helpful in the making of rangeland management decisions. However, it must be cautioned that the range manager/scientist must be an integral part of the computer/data/information system before the potential of remote sensing can be realized.

\section{Image Processing}

According to Mausel (1985), it was not until the mid-1960's that all the elements needed to develop digital image processing approaches to remote sensing became available. Computer-aided interpretation of remotely sensed data requires (1) the availability of digitized spectral (or multispectral) data, (2) advanced computer technology, (3) algorithms applicable to remote sensing, and (4) methodologies or strategies for analysis. These strategies have been slow to develop for resource management and very few are available for use in range management.

Think of your TV set at home. It currently has about 500 lines of resolution, meaning that the resolving power of the system is such that 500 line pairs can be identified on this medium. Such a system is made up of $\mathbf{5 0 0}$ by $\mathbf{5 0 0}$ data elements corresponding to IFOVs each having both spatial and spectral aspects. The spatial aspect defines the apparent size of the resolution cell and the spectral aspect defines the intensity of the spectral response for that cell (pixel) in a particular waveband. Visual interpretation of a group of like pixels leads the eye to identify discrete clusters, blobs, or polygons and judge them to be recognizable features on a digitized image representing real and meaningful elements of the landscape.

Multispectral data derived from scanners provide radiance or brightness information in each of several discrete wavebands within the electromagnetic spectrum for each pixel. These brightness levels are divided into quantizing levels. Tucker (1979) found that the current 256 quantizing levels of most satellite scanning systems was sufficient for satellite monitoring of vegetation resources. When several of these wavebands are looked at simultaneously we refer to the result as an n-dimensional spectral signature where $\mathrm{n}$ represents the number of spectral bands used. The signatures vary with the scanning device and its sensitivity to the wavelength being measured.

In addition to multispectral scanners, it is possible and feasible to digitize both aerial photographs and video images. This paves the way for computer enhanced digital image processing and interpretation of these digitized images or any available image products. A range management example would be to make canopy cover measurements from large-scale digitized aerial photographs or video images with a classification algorithm used with a PC driven image processing system.

\section{Vegetation Indices}

For live green vegetation there is a significant differential in reflectance and absorption of electromagnetic radiation when going from visible to near or mid infrared wavelengths (Fig. 2). These differences have led to the development of several multispectral band ratios and indices that involve both the red/infrared differences and coefficients derived from several bands. These ratios and indices are indicative of the quantity and quality of green and senescent vegetation. On rangelands, especially arid and semiarid rangelands, soil background conditions and shadows often influence the signal received by a multispectral scanner which acts to complicate the use of these indices for evaluating vegetation (Tueller 1987a).

Jackson et al. (1983) pointed out that an ideal vegetation index would be highly sensitive to vegetation, insensitive to soil background changes and only slightly influenced by atmospheric path radiance. On rangelands the ideal index would have the capability of sorting out the influence of shadow and the influence of the great variety of leaf reflectances among the many species and species groups found as well as the standing dead vegetation and litter (Tueller 1987).

The multispectral or $\mathbf{n}$-space indices originated from Kauth and Thomas (1976), who proposed a transformation that used linear combinations of 4 Landsat MSS bands to produce 4 indices: brightness, greenness, yellowness, and nonsuch. The soil spectra in 4-dimensional Landsat MSS signal space were found to be distributed along a plane, known as the plane of soils (Fig. 4). It is 


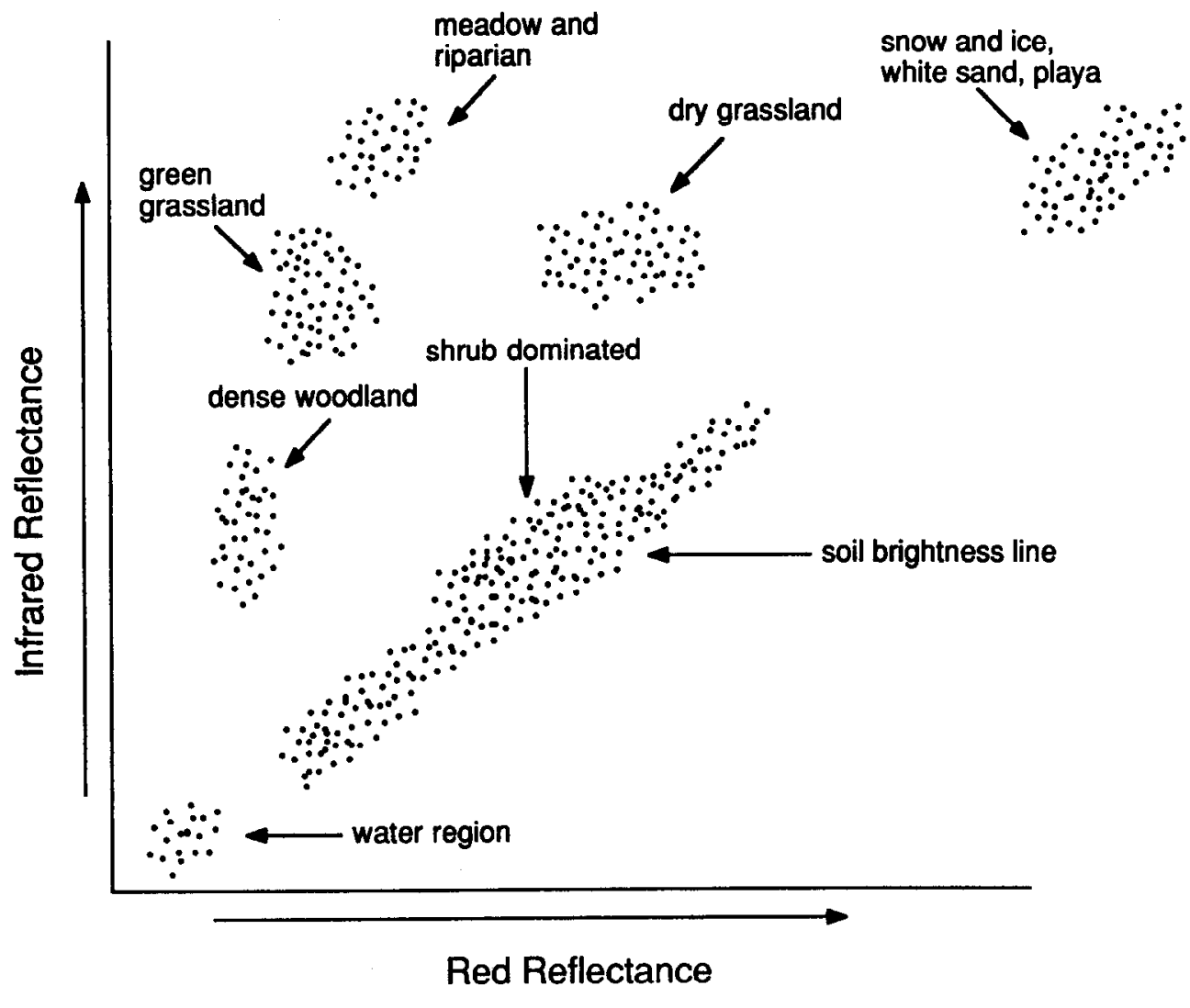

Fis. 4. An infrared/red ratio plot showing the distribution, in spectral space of components of a rangeland scene: dense woodland; green grassland; meadow and rlparian; dry grassland; shrub dominated communities; the plane of soils or soil brightness line; bright objects such as snow, ice, white sand, bright bare soil or dry playa; and water.

sometimes referred to as a soil baseline in 2-dimensional digital space. This observation led to the soil brightness index (SBI) which established the data plane for soils. The SBI is measured as the vector distance in the direction of the soil baseline. The greenness vegetation index (GVI) is defined as the measured distance perpendicular (orthogonal) to the soil baseline towards a point of all vegetation (Kauth and Thomas 1976). Figure 4 shows the distribution in infrared/red spectral space of pixels from various range landscape types.

The perpendicular vegetation index (PVI) is a combination of infrared and red bands (Richardson and Wiegand 1977). This 2-dimensional n-space equivalent of the GVI has been defined as the orthogonal distance of a given spectral point from the soil baseline. The PVI responds to changes in both the quality and quantity of vegetation. The PVI, unlike ratio-based indices, minimizes the influence of the soil background for the assessment of green biomass (Elvidge and Lyon 1985).

Ratio-based indices for vegetation assessment typically use the red and near-infrared (NIR) bands. They contrast the high chlorophyll absorption region in the red against the high reflectivity in the NIR. The ratio between the NIR and red radiations was found to be a sensitive indicator of green biomass (Tucker 1979). These indices include the ratio vegetation index where $R V I=N I R /$ red and the normalized difference vegetation index (NDVI) where ND $=(\mathrm{NIR}+\mathrm{red}) /(\mathrm{NIR}-\mathrm{red})$. The ND increases as the vegetation becomes greener or more dense. A modified normalized difference (MND) is a ratio based index where MND = (NIR - $\left(1.2^{*} \mathrm{red}\right)$ )/(NIR + red). Tucker (1979) and Jackson and others (1983) give thorough descriptions of ratio-based indices.

Paltridge and Barber (1988), in a study of arid lands in Australia, produced the MND by modifying the NDVI to include the slope of the best-fit line for lands with low vegetation cover. The MND maximizes the contrast in "greenness" while assigning a value of zero for no vegetation or dry vegetation. Huete's (1988) soiladjusted vegetation index (SAVI) is a similar modification of the NVDI. A constant of 0.5 was recommended for sites with intermediate amounts of vegetation. Ratio-based indices are relatively independent of illumination intensity and eliminate the irradiance measurements required for the calculation of reflectances (Pinter et al. 1983).

Spectral response from any land area (including rangelands) and any sensor depends on numerous variables that must be evaluated alone and in various combinations. These characteristics include such things as: (a) vegetation cover by species, (b) total vegetation cover, (c) species or vegetation structure or geometry, (d) leaf geometry, (e) bare ground percentage, (f) amount of shadow, (g) cryptogam cover on the bare soil, (h) lichen cover on soils and rocks, (i) algal mats, (j) microbial desert crusts, (k) gravel and/or pavement, (l) standing dead vegetation, and (m) topography. These factors along with such factors as season, time of day, solar zenith angle (Singh 1988), soil moisture, soil and foliage color, and vegetation maturity all contribute noise to vegetation indices.

To understand these variables there is a recognized need to carefully examine the spectral characteristics of various rangeland scenes and components of those scenes. For example, Asrar et al. (1985) found that burned and unburned tallgrass prairie grass canopies showed distinctly different, diurnal and seasonal, spectral reflectance characteristics in the visible and infrared regions of the spectrum. Musick (1984) found that green vegetation indices tended to remove the influence of shrubs in New Mexico mesquite/grass vegetation that were green in June, giving an estimate of grass cover. Tueller and Oleson (1989) described fluctuations in radiance 
values of pixels in arid shrubland vegetation depending upon differences in ground target, latitude, time of year and time of day.

\section{Pixel Modelling}

Pixel modelling can be defined as any procedure whereby the spectral mixture inherent in an individual pixel can be separated into various known components. Several approaches have been used. Gladwell (1982) used reflectance radiometry and the resultant wavelength spacing and shape of the absorption features of various clay minerals to separate component spectra from pixels using a deconvolution procedure. Pech et al. (1986) used a class of statistical models called mixture models as a framework for the analysis of ieflectance from multi-component surfaces.

Adams et al. (1982) compared airborne or TM pixel samples with ground-obtained spectra in terms of their proportionate mix of ground level spectra that approximate the reflectance characteristics of pixels in the sample. Wilson and Tueller (1987) used a similar approach and found that the composite ground signatures indicate that spectrally dark components exist in rangeland plant communities which decrease the brightness of a scene measured from the air. Shadow and litter are presumed to be the primary sources of darkening.

Huete (1986) adapted a factor-analysis inversion model to decompose a data set of spectral mixtures into a sum of unique reflecting components weighted by their corresponding amounts Pech et al. (1986) studied how the landscape components, each covering a fraction of the total area, contribute to the measured reflectance on rangelands in Australia. Heilman and Boyd (1986), Richardson and Wiegand (1977), and Huete et al. (1984) all considered the effect that soil background has on the vegetation component of the pixel as they attempted to discriminate bare soil from low vegetation densities typical of arid rangelands.

Development of improved procedures for evaluating individual pixels should lead to improved applications of remote sensing to rangeland management problems. An example is the potential to look at a rangeland scene on 2 dates and determine the change that has taken place, either in terms of changes in accumulated biomass, level of productivity, degree of use or changes in the composition of dominant species that can be indicative of range trend. In this latter case the reference might be to modelling pixels to determine if the spectral information can give a clear picture of the relative proportions of green woody vegetation, green non-woody vegetation, standing dead vegetation, litter, bareground, gravel, rock and other parameters that are related to ecological conditions and trend.

\section{Rangeland Applications}

Rangeland applications have been described in several papers (Carneggie 1968; Haas et al. 1975; Maxwell 1976; Poulton 1975; Thompson 1977; Tueller 1979b, 1982, and 1983; Poulton 1985). Applications of remote sensing are best thought of as existing as part of a remote sensing cycle or a list of valid steps (Tueller 1983):

I Define the problem and seek information.

II Determine the appropriate remote sensors.

III Acquire the remotely sensed data.

IV Correlate the data with ancillary ground data.

V Analyze the data for its information content.

VI Report and/or publish the information.

VII Interpret and use the information;

or as systematic models relating ancillary ground data to remotely sensed data (Maxwell 1976). Poulton et al. (1975) described the broad functions of resource allocation and management on rangelands and described training requirements and procedures for operational work flows involving remote sensing. Still the number of useful and fully applied procedures or techniques is appallingly low.

\section{Rangeland Vegetation Mapping}

Range managers are interested in the distribution and condition of the vegetation and forage base as it occurs in space and time. Areas of rangeland vegetation can be mapped from space or aircraft altitudes with reasonably high levels of accuracy using multispectral data and image processing systems. Photo interpreters with training in range management, plant ecology and soils, and with field experience in the area in question, can map the various plant communities or ecological sites. These interpreters, after gaining experience can effectively use vertical aerial photographs at various scales and stero viewing to map homogeneous polygons bounded by ecotones that represent vegetation communities.

In the Great Basin Tueller (1979a) found that a scale of $1: 10,000$ is optimum to map at the habitat type or ecological site level. However, many of these same features can be mapped at resource photography scales (e.g., 1:24,000). Photo interpretation of 1:1,000,000 scale Landsat 1 images allowed the mapping of the major vegetation zones in the Great Basin (Tueller et al. 1975). One can develop a map with good accuracy for a given area with remotely sensed data obtained at a particular time and date. If, however, the data are projected in either space or time the classifications or mapping accuracy is significantly reduced. This is because we lack understanding of the spectral characteristics of our relatively complex rangeland scenes (Tueller 1987a).

Machine processing techniques to map and evaluate range vegetation communities begin with the creation of spectral class statistics of the pixels representing the area of interest (McGraw and Tueller 1983). Three basic methods used to create spectral class statistics are supervised, unsupervised, and a mixed approach or guided clustering (Rohde 1978).

In a supervised approach, training windows are designated in the data set. These consist of a group of pixels, known to represent a range plant community based on field observations, which have been selected and related to ground data. Statistics describing these windows are generated by the computer (mean and standard deviation) and then extrapolated over the entire area being mapped and a classification and map are derived. A drawback to this approach is that a significant number of pixels are usually not classified because it is difficult to locate and identify homogeneous training sites for all plant communities of interest. Even in highly homogenious plant communities there is still considerable pixel to pixel variability or noise to contend with thus leading to a high percentage of misclassified pixels.

Unsupervised classification approaches have worked best on rangelands. Pixels are clustered into groups of pixels with similar spectral response. The clustering is controlled by setting maximum standard deviation, minimum distance between cluster centers, minimum number of pixels allowed in a cluster or the maximum number of spectral classes that can be generated. This procedure classifies most pixels and can be repeated until the classification is satisfactory, i.e., can be demonstrated to match the features of interest on the real landscape. The idea is to create spectral classes that represent a specific polygon or set of polygons on the ground. These polygons represent what are termed spectral classes which have unique spectral characteristics within the limits that have been set for the wavebands used. The interpretation question is whether or not these spectral classes actually represent what may be termed information classes, i.e., discrete polygons on a range landscape that represent specific plant communities or other features with unique attributes. Information classes can represent plant communities, grazing allotments, range seedings, successional communities (sites of a known range condition) or other features. 


\section{Other Rangeland Management Application}

What else can remote sensing do for range managers? In range management it is important to know what is happening to individual species. For this reason considerable technology has developed around small-format cameras with either $35 \mathrm{~mm}$ or $70 \mathrm{~mm}$ format (Carneggie and Reppert 1969, Heintz et al. 1978, Carneggic et al. 1971, Reppert and Driscoll 1970, Poulton et al. 1975, Tueller 1978, Waller et al. 1978, Everitt et al. 1980, Meyer et al. 1982, Everitt 1985 and Tueller 1987b and Tueller et al. 1988). These cameras provide photographic scales from 1:500 to 1:2,000 or smaller and are useful for identifying many species and making detailed measurements. However, since the format is small and the scales large, limited area coverage requires creative sampling to provide adequate data and make valid projections concerning rangeland areas of interest.

Based on field experience we can use aerial photographs to identify features, judge their significance, measure their number or extent (inventory), and determine over time using subsequent photographs whether or not significant changes have taken place (monitoring). Both black-and white-panchromatic (photographs taken where the emulsion is sensitive to the total range of the visible part of the spectrum), color, and color infrared photographs are used. Color and color infrared film studied in concert usually provides more total information than black-and-white, color, or color infrared alone. The added information in color products justifies the extra cost for most uses on most rangelands.

Grazing management can be evaluated and monitored using remote sensing imagery. Repeat photography or imagery either with film cameras, video cameras, or digital image products at appropriate scales can provide baseline information on range readiness, utilization, distribution of livestock, and other parameters of interest. Pickup and Chewings (1988) used Landsat imagery along with animal distribution models to estimate the distribution of grazing and patterns of cattle movement in large arid zone paddocks in Australia. Applications to intensive grazing management systems are exemplified by the ability to follow the influence of changes in grazing of the vegetation.

Vegetation productivity and biomass levels are of intense interest to range managers. Using Landsat MSS data McDaniel and Haas (1982) found that the GVI was highly correlated with wet green yield, dry green yield and cured vegetation cover on mesquite-grass vegetation. They concluded that quantitative measurement of rangeland vegetation condition can be made from Landsat MSS data.

Remote sensing has also been used to map and inventory rangeland soils. Westin and Lemme (1978) successfully mapped soils although they were acutely aware of the influence of the vegetation on the spectral signatures. Landsat has been used to distinguish between eroding, stable, and depositional soil environments in central Australia (Pickup and Nelson 1984). Their procedure worked best when they there was a uniform level of greenness in the vegetation. Attempts have been made to predict soil loss from space-acquired remotely sensed data (Spanner and others 1983) but the techniques require additional research before they can be deemed successful. Gully erosion on rangelands is probably best measured with vertical stereo aerial photographs (Welch et al. 1984)

Watershed studies on rangelands can be enhanced by remote sensing. Zevenbergen (1985) found high correlations between rangeland runoff curve numbers and various reflectance indices obtained from Landsat MSS data. The boundaries of watersheds can be easily mapped on various scales of aerial photographs. Color infrared aerial photographs or digital spectral maps can be used to map riparian vegetation as well as areas of recharge and discharge in water balance studies. Water quality in streams, sedi- mentation changes as a result of upstream and rangeland watershed activities can be assessed using various spectral signatures. Remote sensing can provide spatial and temporal information on properties of soils related to erosion, hydrology, and productivity (Ritchie 1983).

Wildlife habitat parameters in rangeland environments can often be best evaluated and measured using remote sensing procedures (Tueller 1980). Both terrestrial and wetland habitats can be so assessed. Examples of the former include mapping of deer winter ranges with stands of bitterbrush, mountain mahogany habitats or patches of aspen used for summer escape cover. Tueller et al. (1978) used Landsat digital maps to evaluate emu habitat in West Australia. Asherin and associates (1978) used land cover maps emphasizing vegetation for predicting avian use of sections of land in southeastern Montana. Examples of the latter include color aerial photographs useful for marshland evaluations (Seher and Tueller 1973) and for riparian area management (Hayes 1976; Batson et al. 1987).

\section{Geographic Information Systems}

Geographic information system (GIS) technology is relatively new but is growing extremely rapidly. A GIS is an information technology system which stores, analyzes, and displays both spatial and non-spatial data (Parker 1987). Furthermore, spatial data occur in 3 forms, points, lines, and polygons or areas. All features on a range landscape can be reduced to one of these categories. This technology has evolved as a result of the need to use mappable information to make decisions concerning preservation of land resources based on a range of institutional, political, economic, and environmental data concerns. GIS are powerful tools for integrating and analyzing data derived from remotely sensed imagery interpretations, soil surveys, vegetation maps, land ownership maps, utilities maps, water resources, geology, mining, and many other potential themes that can be presented spatially. These geographically referenced data sets are spatially registered so that multiple themes of data can be quickly compared and analyzed together.

Because many GIS applications are in their infancy, a large proportion of time is currently expended on data base creation (Johnston 1987). This is a modelling process wherein the manager is creating digital, spatially oriented maps that are easily accessed. The focus is on the development of land management models that can integrate several submodels created to analyze individual management objectives, e.g., an assessment of rangeland monitoring data in relation to land ownership, class of livestock, wildlife populations, and associated vegetation changes warranting management alterations.

For range management we might overlay, one-on-the-other, spatial data on vegetation, soils and soil suitability interpretations, water resources, roads, fences, improvements, wild life summer and winter ranges, grazing management systems, use maps, range condition maps, carrying capacity or productivity data, ecological sites, habitat types, and land ownership. Many other such themes can be looked at individually or collectively to aid the range manager to place all conflicting uses and data types quickly and efficiently into a proper perspective for rapid efficient interpretation, evaluation and action.

H. Dennison Parker, whose leadership and insight into GIS systems and their utility for natural resources including rangelands, has quoted Light (1986) who analyzed the storage requirements for a digital database containing all 54,000 7.5' quadrangle maps required to cover the lower 49 states. Light concluded that $10^{14}$ bits of data would be required for a ground spatial resolution of 1.7 meters, and that all the resulting data could be stored on 4000 optical disks smaller than a phonograph record. "What's the signif- 
icance to global assessments? Well, if you compute storage requirements at hectare ground resolution, a level which would be very useful in many developing countries, a similar spatial data base for the whole continent of Africa could be stored on 5 optical disks." These data would include all the rangelands, and such storage levels would allow additional themes to be stored and retrieved as management levels increase.

Caution must be taken to see that only correct and necessary data sets are entered into the GIS and that the tendency to place everything available into the data base does not get out of hand. Also personnel retraining requirements present a significant problem. However, GIS systems are certainly going to be a large part of remote sensing data analysis. Considerable rangeland management data will be spatially displayed, overlayed, and importance given to the juxtaposition of the many data points as managers use this powerful tool to quickly and accurately make management decisions.

\section{Economic Considerations}

Little has been written about the costs of remote sensing with the exception of the contracting of aerial photography. Current costs, including aircraft mobilization costs, film processing and special products can be agreed upon ahead of the job to be done by the numerous aerial photo firms around the world. Costs are usually quite reasonable unless there is a need for repeat photography which might be required for rangeland monitoring and even this can often be reasonably costed out. A recent consideration for aerial photo acquisition indicates that one firm would charge approximately $\$ 3,000$ to provide 200 exposed and processed positive transparencies in a $9^{\prime \prime}$ format. These costs included aircraft mobilization costs, cameraman, pilot, aircraft (including climb and descent times), color films, and film processing. These $\mathbf{2 0 0}$ frames could cover a large or small area depending upon the length of the lens and flight altitude.

For repeat coverage digital multispectral information on computer compatible tapes may be less expensive. Much of this cost was, previously, borne by NASA and NOAA. However, if one were to amortize the cost of the spacecraft development, system development, launch, etc., the cost would likely be prohibitive. Since privatization of Landsat the costs of Landsat computer compatible tapes have skyrocketed.

The cost for a single scene for a single date ( 7 TM bands) is, as of this writing, $\$ 3,600$, which can become costly if multiple dates of imagery are required for a range management application. Even a 512 by 512 pixel portion of a scene down-loaded to a floppy disk for use on a PC is remarkably expensive at $\$ 600$ for the 7 bands. It seems clear that one must be careful in sampling and know precisely the areas one needs to study or evaluate before purchasing either digital, photographic image, or satellite computer compatible tapes or disks. This leaves video as possibly the least costly remotely sensed data for rangeland management. The principal cost for a video system once the initial capital expenditure for equipment, including camera, recorder, etc., has been met, is for the plane and pilot. A multispectral video camera system can be obtained for twenty to thirty thousand dollars (personal communication, J.H. Everitt).

Remote sensing, either aerial or satellite, has the potential to reduce the ratio of field to office time. For many range management requirements, this would constitute a real saving of manpower and field mobilization costs.

\section{Developing Countries}

Surveys for management of the vast rangelands of the Third World should be done in scales between 1:200,000 and 1:250,000 (Zonneveld 1978). Larger scales tend to just produce an informa- tion overkill. However, smaller scales, such as Landsat images have been very useful. In most developing countries space or satellite remote sensing data is the only source of new or up-to-date information about natural resources. In this sense the data is invaluable for rangeland resource inventory, development, and monitoring. For the near future, satellite imagery, generally visually interpreted, will offer the best option for most developing countries to document the condition and extent of their natural resource base and to monitor their progress or failures in husbanding and developing range resources (personal communication, C.E. Poulton 1989).

Remote sensing with both aerial photography and satellite imagery, singly and in combination, is being applied to range management problems in many Third World countries such as Kenya (Isavwa 1988), Niger (Hiernaux 1988), India (Mehta 1988), Egypt (Gad and Daels 1986), Botswana (Ringrose and Matheson 1983), Sudan (Heilkema et al. 1986), Senegel (Tucker et al. 1985), Tanzania (Poulton 1979), Mauritania (Dalsted 1988); and many other countries.

Poulton's (1979) plan for the use of Landsat imagery in Tanzania is excellent although its implementation is made difficult by social and political constraints. His study included a $1: 1,000,000$ mosaic of the region with climatic overlays and an interpretation, by Land Systems, of land use capability for both pastoralism and agricultural cropping. Interpretation was based on knowledge of $550 \mathrm{Land}$ Units (vegetation-landform complexes). Poulton concluded that little benefit was realized from the study for a number of reasons, mostly not related to the professional quality of the work done. The reasons were attributed to a lack of direct involvement of country nationals, to the failure to provide follow-up continuity, and to the level of understanding that was possible to create in the short time span of the study.

Dalsted (1988) discribed a Landsat/GIS approach for Mauritania but considered it a first step in assessing the natural resources of the study area. Three important overlays were produced, forest regeneration, soil erosion hazard, and rangeland carrying. Both studies suggest that good field data and suitable resource classifications must be developed within the country before the Landsat imagery can be adequately interpreted. With appropriate institutional organization and efforts of newly trained scientists and managers, the applications of remote sensing will someday become commonplace throughout the world and, at the same time, serve to improve the management of rangelands in developing countries.

\section{Training and Education}

An impediment to rapid application of remote sensing science to rangeland resources management is the lack of individual workers educated in both remote sensing and range management. Very few range management professionals receive training in remote sensing (Tueller 1983). Those that have such training often do something else rather than remote sensing when employed in range management.

There are 2 or 3 solutions; one is inservice education of range conservationists or scientists already working in the field. The idea would be to develop a skilled photointerpreter and remote sensing analyst with expertise in landscape ecology and experience in digital image processing and GIS. Such an analyst should be able to support the information needs of his management colleagues. He or she would conduct the surveys and analysis and often make inferences about successional status, or range condition and trend, and interpret the impacts of resource use and management (Poulton 1975). A second solution would be to provide range students with a working knowledge of photointerpretation, remote sensing, and GIS while they are still in school although this might entail a program going beyond the traditional 4 years.

A final and least desirable approach would be to have range 
managers work closely with remote sensing specialists. This latter approach has not worked well. Remote sensing specialists with backgrounds in physics, computer science, or engineering, who are not knowledgeable of vegetation and soil science, end up making many of the image analysis decisions as well as the range management interpretations of the data. This should be strenuously avoided. It just doesn't work. Those who require the information should use the remote sensing procedures themselves to obtain the data which they will then interpret based on sound ecological and range management experience and familiarity with the field problems and locations involved.

The adaptation of remote sensing science to the solution of range management problems will have to await the further training of individuals in both remote sensing and range management. It is important to provide continuity of personnel capable in remote sensing between the inventory and monitoring work and the processes of information use and decision making. Emphasis must be given to key training elements of range management, vegetation science, plant ecology, soils, and vegetation-landform-soils relationships. If understanding of these basic elements is lacking, the interpretation job simply doesn't get done.

\section{Conclusion and the Future}

The future of rangeland remote sensing is a bit hazy. It seems fair to conclude that research concerning the spectral characteristics of heterogeneous rangeland scenes using high resolution systems, ground radiometers, and ancillary data will lead us closer and closer to an ability to use remote sensing to quickly and efficiently measure many parameters of interest.

Near real time video systems coupled with digital image analysis approaches and GIS data bases will become routine in the next few years as range managers realize the great potential of these systems. Perhaps airborne video remote sensing technology will be the single most useful new technology for rangeland applications. As range managers become educated or trained in and feel comfortable with remote sensing data and PCs, then high-technology remote sensing for range management will have come of age.

One can visualize range conservationists obtaining the majority of their required management information from remote sensing instruments within, say, 20 years. Poulton (1981) reminded us that remote sensing is not a panacea and that its effective use increases rather than decreases the demand that the analyst thoroughly understand the ecology of the landscapes with which he or she works. And finally, Haas (1986) has cautioned us that to realize these applications, there will have to be achieved support in the administrative and managerial echelons.

\section{Literature Cited}

Adams, J.D., M. Smith, and J.B. Adams. 1982. Use of laboratory spectra for determining vegetation assemblages in Landsat images. Proc. Internat. Symp. Rem. Sens. of Environ., Fort Worth., Dec.

Asherin, D.A., J.E. Roelle, and H.L. Short. 1978. Characterization of terrestrial vertebrate habitats using remotely sensed imagery. Proceedings Pecora IV Symposium. Oct. Sioux Falls, South Dakota. pp 274-279.

Asrar, G., R.B. Myneni, Y. L, and E.T. Kanemasa. 1985. Measuring and modeling spectral characteristics of a tall grass prairie. Remote Sens. Environ. 21:143-155.

Bateon, F.T., P.E. Cuplin, and W.A. Crisco. 1987. The use of aerial photography to inventory and monitor riparian areas. USDI-BLM, Riparian Area Management, Tech. Ref. 1737-2.

Carnectie, D.M. 1968. Analysis of remote sensing data for range resource management. Annu. Prog. Rep. Offices of Space Sciences and Application, NASA, Washington, D.C..

Carnecele, D.M., and J.N. Reppert. 1969. Large scale $70 \mathrm{~mm}$ aerial color photography. Photogramm. Eng. 35:249-257.

Carnetgle, D.M., D.G. Wilcox, and R.B. Hacker. 1971. The use of large scale aerial photographs in the evaluation of western Australia rangelands. Tech. Bull. 10. Dep. Agr. West. Aust., Perth, West Aust..
Colwell, R.N. (edttor in chien). 1583. Manual of remote sensing, Second Ed., Vol. I. Amer. Soc. Photogramm., Falls Church, Va.

Dalited, K.J. 1984. The use of a Landsat-based soil and vegetation survey and graphic information system to evaluate sites for monitoring desertification. Desert. Contr. Bull. 16:20-26.

Elvidge, C.D., and R.J.P. Lyon. 1985. Influence of rock-soil spectral variation on the assessment of green biomass. Rem. Sens. of Environ. 17:265-279.

Dlvidge, C.D. 1989. Visible and near infrared reflectance characteristics of dry plant materials. Inter. J. Rem. Sens. (in Press).

Everitt, J.H., A.H. Gerberman, M.A. Alunin, and R.L. Bowen. 1989. Using $70-\mathrm{mm}$ aerial photography to identify rangeland sites. Photogramm. Eng. and Rem. Sens. 47:1357-1362.

Everitt, J.H. 1985. Using aerial photography for detecting blackbrush (Acacia rigidula) on south Texas rangelands. J. Range Manage. 38:228-231.

Everitt, J.H., and P.R. Nixon. 1985. Video imagery: a new remote sensing tool for range management. J. Range Manage. 38:421-424.

Everitt, J.H., M.A. Huscey, D.E. Escobar, P.R. Nixon, and B. Pinkerton. 1986. Assessment of grassland and phytomass with airborne video imagery. Rem. Sens. of Environ. 21:299-306.

Everitt, J.H., and D.E. Decobar. 1999. The status of video systems for remote sensing applications. Proc. 12th Bienn. Workshop on the Use of Color Photography and Videography in the Plant Sciences and Related Fields. Reno, Nevada. (In Press).

Gad, A., and L. Daets. 1986. Assessment of soil degradation in an arid region using remote sensing. Proc. IGARSS' 86 Symposium, Zurich. p. 1241-1246.

Gladwell, D.R. 1982. Application of reflectance spectrometry to clay mineral determination in geological materials using portable radiometers. Proc. Inter. Symp. Remote Sens. Environ., Fort Worth.

Graetz, R.D., and J.A. Ludwis. 1978. A method for the analysis of piosphere data applicable to range assessment. Aust. Range. J. 1:126-136.

Green, G.M. 1986. Use of SIR-A and Landsat MSS data in mapping shrub and intershrub vegetation at Koonamore, South Australia. Photogramm. Eng. and Rem. Sens. 52:659-670.

Han, R.H., D.W. Deering, J.W. Roune, Jr., and J.A. Schell. 1975. Monitoring vegetation conditions for Landsat for use in range management. p. 507-568. In: Proc. NASA Earth Resources Symp. NASA. Houston, Texas.

Haas, R.H. 1986. A new view for resource managers. Rangelands. 8:99-102. Hayes, F. 1976. Application of color infrared $70 \mathrm{~mm}$ photography for assessing grazing impacts on stream-meadow ecosystems. Sta. Note 25, Univ. Idaho, Forest, Wildl. and Range Exp. Sta..

Hellkema, J.U., S.D.Prince, and W.L. Astle. 1986. Rainfall and vegetation monitoring in the Savanna Zone of the Democratic Republic of Sudan using the NOAA advanced very high resolution radiometer. Inter. J. Rem. Sens. 7:1499-1514.

Hellman, J.L., and W.E. Boyd. 1986. Soil background effects on the spectral response of a three-component rangeland scene. Rem. Sens. of Environ. 19:127-137.

Heintz, T.W., J.K. Lewis, and S.S. Waller. 1978. Low-level aerial photography as a management and research tool for range inventory. J. Range Manage. 32:247-249.

Hiemanx, P. 1988. Application of remote sensing techniques for the quantification of range resources changes in the Sahel. Abstr. Vol. I, Third Inter. Range. Congr., Range Manage. Soc. of India. Vigyan Bhavan, New Delhi. p. 36.

Huete, A.R. 1986. Separation of soil-plant spectral mixtures by factor analysis. Rem. Sens. of Environ. 19:237-251.

Huete, A.R. 1989. A soil-adjusted vegetation index (SAVI). Rem. Sens. of Environ. 25:295-309.

Huete, A.R., D.F. Pout, and R.D. Jackeon. 1984. Soil spectral effects on 4-space vegetation discrimination. Rem. Sens. of Environ. 15:155-165.

Ieavwa, L.A. 1988. Inventory and monitoring of rangeland resources in Kenya using remote sensing techniques. Abstr. Vol. I, Third Inter. Range. Congr. Range Manage. Soc. of India. Vigyan Bhavan, New Delhi p. 36.

Jackson, R.D., P.N. Slater, P. Pinter Jr., 1983. Discrimination of growth and water stress in wheat by various vegetation indices through clear and turbid atmospheres. Rem. Sens. of Environ. 13:187-208.

Jenaen, J.R. 1981. Urban change detection mapping using Landsat digital data. Amer. Cartographer. 8:127-148.

Johnaton, K.M. 1987. Natural resource modeling in the Geographic Information System Environment. Photogramm. Eng. and Rem. Sens. 53:1411-1416. 
Kahle, A.B., and A.F.H. Goetz. 1983. Mineralogic information from a new airborne thermal infrared multispectral scanner. Sci. 222:24-27.

Kauth, R.J., and G.S. Thomas. 1976. The tasseled-cap-a graphic description of the spectral-temporal development of agricultural crops as seen by Landsat. Proc. Machine Processing of Remotely Sensed Data. IEEE Cat. 76 CH 1103-1 MPRSD. LARS. p. 4b-41-51.

Langley, P.G. 1971. Multistage sampling of earth resources with aerial and space photography In: Colwell, R.N. (Ed) Monitoring Earth Resources from Aircraft and Spacecraft: NASA SP-275, p 129-141.

Langran, K.J. 1985. Monitoring vegetation recovery patterns on Mount St. Helens using thermal infrared multispectral data. The TIMS Data User's Workshop Nat. Space Tech. Lab., Mississippi. JPL Pub. 86-38.

Light, D.L. 1986. Mass storage estimates for the digital mapping era. Photogramm. Eng. and Rem. Sens. LII:419-425.

Lusch, D.P. 1988. Super VHS for improved airborne CIR videography. Proc. 1st Workshop on Videography. Amer. Soc. Photogramm. and Rem. Sens. p 23-29.

Mausel, Paul W. 1985. Characteristics and techniques of computer assisted processing of spectral data. pp. 292-309 In: The Surveillance Science. Remote Sensing of Environment. Robert K. Holz (ed). Second Ed. John Wiley and Sons, Inc.

Maxwell, E.L. 1976. A remote rangeland analysis system. J. Range Manage. 29:66-72.

McDaniel, K.C., and R.H. Haas. 1982. Assessing mesquite-grass vegetation from Landsat. Photogramm. Eng. and Rem. Sens. 48:441-450.

McGraw, J.F., and P.T. Tueller. 1983. Landsat computer-aided analysis techniques for range vegetation mapping. J. Range Manage. 36:627-631.

Mehta, M.S. 1988. Thematic mapper data for evaluation and management of range ecosystems in part of Madhya Pradesh. Abstr. Vol. I, Third Inter. Range. Congr., Range Manage. Soc. of India, Vigyan Bhavan, New Delhi. p 36-37.

Meyer, M., F. Batson, and D. Whitmer. 1982. Helicopter-borne $35 \mathrm{~mm}$ acrial photography applications to range and riparian studies. Remote Sensing Lab. Univ. Minnesota, St. Paul. IAFHERSL Res. Rep. 82-1.

Miller, D.A., G.W. Petereon, and A.B. Kahle. 1986. Soil and geomorphic studies in arid region using the Thermal Infrared Multispectral Scanner (TIMS). Paper presented at the 3rd Arid Lands Remote Sensing Workshop, Univ. Arizona. Tucson, Apr.

Moyer, R.H. 1950. Some uses of acrial photography in connection with the production and marketing programs of the U.S. Department of Agriculture. Photogramm. Eng. 36:305-307.

Musick, H.B. 1984. Assessment of Landsat multispectral scanner spectral indexes for monitoring arid rangeland. IEEE Trans. on Geosci. and Rem. Sens. Ge-22:512-519.

NASA 1987. HIRIS High-Resolution Imaging Spectrometer:Science Opportunities for the 1990's. Earth Observing System Volume IIc. Instr. Panel Rep.

Paltridge, G.W., and J. Barber. 1988. Monitoring grassland dryness and fire potential in Australia with NOAA/AVHRR data. Rem. Sens. of Environ. 25:381-394.

Parker, H.D. 1987. What is a Geographic Information System? Proceed. Vol. I GIS 87 2nd. Annu. Inter. Conf. on Geograph. Informat. Sys. San Francisco. pp 72-80.

Pech, R.P., R.D. Gruetz, A.W. Davis. 1986. Reflectance modeling and the derivation of vegetation indices for an Australian semi-arid shrubland. Inter. J. Rem. Sens. 7:389-403.

Pickup, G., and D.J. Nelson. 1984. Use of Landsat radiance parameters to distinquish soil erosion, stability, and deposition in Arid Central Australia. Rem. Sens. of Environ. 16:195-209.

Plekup, G., and V.H. Chewings. 1988. Estimating the distribution of grazing and patterns of cattle movement in a large arid zone paddock: an approach using animal distribution models and Landsat imagery. Int. J. Rem. Sens. 9:1469-1490.

Pinter, P.J., Jr., R.D. Jackeon, S.B. Idso, and R.J. Reginato. 1983. Diurnal patterns of wheat spectral reflectances. IEEE Trans. Geosci. Rem. Sens. GE-21:156-163.

Porter, W.A., and H.T. Enmark. 1987. A system overview of the airborne visible/infrared imaging spectrometer (AVIRIS). p. 3-12. In: G. Vane (ed.). Airborne Visible/Infrared imaging spectrometer (AVIRIS), A Description of the Sensor, Ground Data Processing Facility, Laboratory Calibration, and First Results. NASA Jet Propulsion Laboratory. JP. Pub. 87-38.

Poulton, C.E. 1975. Range resources: inventory, evaluation and monitoring. Chap. 18, p. 1427-1478. In: R.G. Reeves (Ed.) Manual of Remote Sensing. Amer. Soc. Photogramm. Falls Church, Va.
Poulton, C.E. 1979. Uses of Landsat imagery in resource analysis of the Masai steppe region in northern Tanzania. Proc. of Rem. Sens. for Natur. Res.; A Symp. Moscow, Idaho pp 361-392.

Poulton, C.E. 1981. The role of remote sensing in making decision about natural resources. Sixth Internat. Training Course in Rem. Sens. Appl. for Past. and Range. Dev. Rome. May p. 81-102.

Poulton, C.L. 1985. Evolution of remote sensing in range management, Speculations on its future. Proc. of Pecora 10 Rem. Sens. in Forest and Range Res. Manage. Fort Collins, Colo., Aug. pp 2-17.

Reppert, J.N., and R.S. Driacoll. 1970. 70-mm Aerial photography-A remote sensing tool for wildland research and management. In USDA, Forest Service. Range and Wildlife Habitat Evaluation, a Res. Symp. pp. 190-193. USDA Forest Serv. Misc. Pub. 1147.

Richardson, A.J., and C.L. Wlegand. 1977. Distinguishing vegetation from soil background information. Photogramm. Eng. and Rem. Sens. 43:1541-1552.

Ringrose, S., and W. Matheson. 1983. Desertification in Botswana: progress towards a viable monitoring system. Desert. Contr. Bull. 9:6-8.

Rftchie, J.C. 1983. Remote sensing and erosion research. Proc. Natur. Res. Model. Symp. Pingree Park, Colo. p 449-450.

Rohde, W.G. 1978. Digital image analysis techniques required for natural resource inventories. AFIPS Conf. Proc. Vol. 47. USDI Geol. Surv. EROS Data Center, Sioux Falls, S. Dak.

Singh, S.M. 1988. Lowest order correction for solar zenith angle to Global Vegetation Index (GVI) data. Int. J. Rem. Sens. 9 (10 \& 11):1565-1572.

Seher, J.S., and P.T. Tueller. 1973. Color aerial photos for marshland. Photogramm. Eng. 34:489-499.

Spanner, M.A., A.H. Strahler, and J.E. Extes. 1983. Soil loss prediction in a geographic information system format. pp. 89-102 In: Proc. on Rem. Sens. of Environ., Ann Arbor, Mich. May.

Thompeon, M.D. 1977. Remote sensing of rangelands in western Canada. pp. 1,506-1,514. In: Proc. Eleventh Internat. Symp. on Rem. Sens. of Environ. Environ. Res. Inst. Michigan, Ann Arbor, Mich.

Tucker, CJ. 1979. Radiometric resolution for monitoring vegetation, how many bits are needed? NASA Tech. Mem. 80293.

Tueker, C.J., and C.O. Justice. 1983. Satellite remote sensing of desert spatial extent. Deser. Contr. Bull. 9:2-5.

Tucker, C.J., C.L. VanPraet, M.J. Sharman, and G. Van Itteraum. 1985. Satellite remote sensing of total herbaceous biomass production in the Senegalese Sahel: 1980-1984. Rem. Sens. of Envir. 17:233-249.

Tueller, P.T., G. Lorain, R. Halvornon, and J.M. Ratlifi. 1975. Mapping Vegetation in the Great Basin from ERTS-I Imagery. Proc. Amer. Soc. Photogramm. 41st Annu. Meeting. March Washington, D.C. pp. 338-370.

Tueller, P.T. 1978. Large scale $70 \mathrm{~mm}$ photography for range resources analysis in the western United States. Proc. 11 th Inter. Symp. on Rem. Sens. of Environ. Ann Arbor, Mich.. p. 1057-1514.

Tueller, P.T., F.R. Honey, and I.L. Tapley. 1978. Landsat and photographic remote sensing for arid land applications in Australia. Proc. 12th Inter. Symp. on Rem. Sens. of Environ. Manila. p 2177-21291.

Tueller, P.T. 1979a. Some aspects of the use of dichotomous keys to aid in the interpretation of color aerial photographs for vegetation mapping. 7th Bienn. Workshop of Color Aerial Photography in the Plant Sciences. Amer. Soc. Photogramm. Davis, Calif. p 189-200.

Tueller, P.T. 1979b. Rangeland remote sensing interpretation problems. Proc. Rem. Sens. for Natur. Res.: A Symp. Moscow, Idaho pp. 450-465.

Tueller, P.T. 1980. Remote sensing applications for wildlife habitat management. Proc. California/Nevada Sect. Wildlife Soc. Redding Calif. pp. 28-33.

Tueller, P.T. 1982. Remote sensing for range management. Chapter 12, p. 125-140. In: Johannsen and Sanders (eds). Remote Sensing for Resource Management. Soil Conserv. Soc. Amer.

Tueller, P.T. 1983. Rangeland remote sensing: an approach. Proc. RNRF Symp. on the Application of Remote Sensing to Resource Management. Amer. Soc. Photogramm. Seattle, Wash. p. 42-45.

Tueller, P.T. 1987a. Remote sensing science applications in arid environments. Rem. Sens. of Environ. 23:143-154.

Tueller, P.T. 1987b. Large-scale color aerial photography for monitoring shrub dominated rangelands. Proc. 11th Bienn. Workshop on Color Aerial Photography and Videography in the Plant Sci. and Related Fields. Weslaco, Texas p. 84-95.

Tueller, P.T., P.C. Lent, R.D. Stager, E.A. Jacobsen, and K.A. Platou. 1988. Rangeland vegetation changes measured from helicopter-borne 35 mm aerial photography. Photogramm. Eng. and Rem. Sens. 54:609-614.

Tueller, P.T., and S.G. Oleson. 1989. Diurnal radiance and shadow fluctuations in a cold desert shrub plant community. Rem. Sens. of Environ. 27:(In Press). 
Ustin, S.L., B.N. Rock, and R.A. Woodward. 1985. Analysis of substrate and plant spectral features of semi-arid shrub communities in the Owens Valley, California. Proc. Thematic Conf.: Rem. Sens. for Explor. Geol. San Francisco, Calif. pp 347-360.

Vane, G., A.F.H. Goetz, and J.B. Wellman. 1984. Airborne imaging spectrometer: a new tool for remote sensing. IEEE Trans. on Geosci. and Rem. Sen. Vol. GE-22:546-549.

Waller, S.S., J.K. Lewis, M.A. Brown, T.W. Helntz, R.I. Butterineld, and F.R. Gartmer. 1978. Use of $35 \mathrm{~mm}$ photography in vegetation sampling. Proc. Ist Inter. Rangel. Congr. Denver, Colo. p. 517:520.

Welch, R., T.R. Jordan, and A.W. Thomas. 1984. A photogrammatric technique for measuring soil erosion. J. Soil and Water Conserv. 39:191-194.

Weatin, F.C., and G.D. Lemme. 1978. Landsat spectral signatures: studies with soil associations and vegetation. Photogramm. Eng. and Rem. Sens. 44:315-325.
Williams, R.E., B.E. Allred, R.M. Denlo, and H.A. Pouleen Jr. 1968. Conservation, development and use of the world's rangelands. J. Range Manage. 21:355-360.

Willow Run Laboratories. 1978. The University of Michigan Notes for a Program of Study in Remote Sensing of Earth Resources. Houston, Texas.

Wilson, R.O., and P.T. Tueller. 1987. Aerial and ground spectral characteristics of rangeland plant communities in Nevada. Rem. Sens. of Environ. 23:177-191.

Zevenbergen, A.W. 1985. Runoff curve numbers for rangeland from Landsat data. USDA Hydrology Laboratory. Agr. Res. Serv. Tech. Rep. HL85-1.

Zonneveld, I.S. 1978. A critical review of survey methods for range management in the third world with special emphasis on remote sensing. Proc. 1st Internat. Range. Congr. Denver, Colo. p 510-513. 